\title{
Using early life stages of marine animals to screen the toxicity of priority hazardous and noxious substances
}

\author{
Isabel Cunha ${ }^{1}$ Tiago Torres ${ }^{1} \cdot$ Helena Oliveira ${ }^{1}$ Rosário Martins ${ }^{1,3}$. \\ Thomas McGowan ${ }^{2}$ - David Sheahan ${ }^{2}$ - Miguel Machado Santos ${ }^{1,4}$ \\ 1 Interdisciplinary Centre of Marine and Environmental Research \\ (CIMAR/CIIMAR), University of Porto, Rua dos Bragas 289, \\ 4050-123 Porto, Portugal \\ 2 Centre for Environment, Fisheries and Aquaculture Science \\ (CEFAS), Lowestoft Laboratory, Lowestoft, UK \\ 3 Health and Environmental Research Center (CISA), Superior School \\ of Health Technology of Porto, Polytechnic Institute of Porto, \\ Porto, Portugal \\ 4 Department of Biology, Faculty of Sciences, University of Porto, Porto, Portugal
}

\begin{abstract}
This study provides toxicity values for early life stages (ELS) of two phylogenetically distinct marine animal taxa, the sea urchin (Paracentrotus lividus), a deuterostome invertebrate, and the turbot (Scophthalmus maximus), a vertebrate (teleost), when challenged by six hazardous and noxious substances (HNS): aniline, butyl acrylate, m-cresol, cyclohexylbenzene, hexane and trichloroethylene. The aim of the study was to provide preliminary information on toxic effects of representative and relevant priority HNS to assess the risk posed by spills to marine habitats and therefore improve preparedness and the response at the operational level. Selection criteria to include each compound in the study were (1) inclusion in
\end{abstract}

the HASREP (2005) list; (2) presence on the priority list established by Neuparth et al. (2011); (3) paucity of toxicological data (TOXnet and ECOTOX) for marine organisms; (4) behaviour in the water according to the categories defined by the European Behaviour classification system (GESAMP 2002), by selecting compounds with different behaviours in water; and (5) physicochemical and toxicological properties, where available, in order to anticipate the most toxic compounds. Aniline and m-cresol were the most toxic compounds with no observed apical effect concentration (NOAEC) values for sea urchin ranging between 0.01 and $0.1 \mathrm{mg} / \mathrm{L}$, followed by butyl acrylate and cyclohexylbenzene with NOAECs ranging between 0.1 and $1.0 \mathrm{mg} / \mathrm{L}$ and trichloroethylene with NOAEC values that were in the range between 1 and $10 \mathrm{mg} / \mathrm{L}$, reflecting their behaviour in water, mostly vapour pressure, but also solubility and log Kow. Hexane was toxic only for turbot embryos, due to its neurotoxic effects, and not for sea urchin larvae, at concentrations in the range between 1 and $10 \mathrm{mg} / \mathrm{L}$. The concentrations tested were of the same order of magnitude for both species, and it was observed that sea urchin embryos (length of the longest arm) are more sensitive than turbot eggs larvae (hatching and cumulative mortality rates) to the HNS tested (except hexane). For this specific compound, concentrations up to $70 \mathrm{mg} / \mathrm{L}$ were tested in sea urchin larvae and no effects were observed on the length of the larvae. Both tests were found to be complementary depending on behaviour in water and toxicity target of the compounds analysed.

Keywords Marine spill $\cdot$ Hazardous and noxious substances (HNS) - Paracentrotus lividus · Scophthalmus maximus .

Early life stage (ELS) bioassays · Standard European Behaviour Classification (SEBC) 


\section{Introduction}

Hazardous and noxious substances (HNS) are defined as any substances other than oil, which if introduced into the marine environment are likely to create hazards to human health, living resources and other marine life. Furthermore, they can cause damage to amenities and/or interfere with other legitimate uses of the sea (IMO 2000). Whereas there is a good level of knowledge available for the toxicity, behaviour and risk associated with marine oil spills, information for HNS is more limited (Solé et al. 2008; Cunha et al. 2015, 2016; Neuparth et al. 2011). Most oils float on the surface and are immiscible with water, but HNS chemicals exhibit a wider range of behaviours (i.e. either sinking, floating on or readily dissolving in water or forming a gas or evaporating) and may therefore impact marine organisms in different environmental compartments (CEFAS 2009). There is a current paucity of knowledge about the effects of HNS on a wide range of marine biota that might be representative of the different compartments that may be affected by different HNS spills, and the few data that are available on HNS ecotoxicology are mostly from experiments conducted with freshwater organisms (Mamaca et al. 2005; Purnell 2009), making it difficult to predict the effects on marine organisms and to prepare contingency plans for these substances (Neuparth et al. 2011).

One fundamental requirement of bioassays to assess pollution in marine systems is the ecological relevance of the species, a requirement that is met by Paracentrotus lividus and Scophthalmus maximus for East Atlantic areas. Both are native European species of ecological and economic importance. Early life stages (ELS) of these two species were used to enhance the sensitivity to the tests, since ELS are frequently less tolerant to toxicants than adults (Ringwood 1991; His et al. 1999; Mhadhbi et al. 2010). During early ontogenesis, critical development of tissues and organs takes place, a process which can easily be disrupted by unfavourable environmental conditions including exposure to toxic compounds (Foekema et al. 2008).

The sea urchin embryo-larval toxicity test (SET) is frequently used in environmental quality assessment for several reasons: the species is of ecological relevance; is easy to collect, handle and maintain in the laboratory; and has a high survival rate under control conditions and low sensitivity to natural variables (Salamanca et al. 2009). Sea urchin is also considered an ideal tool for marine ecotoxicological tests because it is sensitive to several kinds of organic and inorganic micropollutants (Bellas et al. 2005; Salamanca et al. 2009), including metals (Fernández and Beiras 2001; Salamanca et al. 2009) and emerging pollutants (Ribeiro et al. 2015; Nacci et al. 1986) that may affect the survival of larvae and adult sea urchins, providing an indication of the toxicological effects of contaminants to the whole ecosystem. Furthermore, in vitro fertilization and gamete generation of sea urchin are relatively easy, and test results can be obtained in a short period of time (48 h) (Salamanca et al. 2009). Therefore, SET was considered a rapid, sensitive and cost-effective biological tool for marine monitoring worldwide (Saco-Álvarez et al. 2010; Ribeiro et al. 2015).

The vertebrate teleost fish, S. maximus, is considered a good biological model for toxicological studies (Mhadhbi et al. 2010) due to diverse characteristics, namely its rapid growth rate, efficiency in adapting to diverse food sources, great resistance to diseases, easy reproduction and, finally, good tolerance to a wide range of environmental conditions (Mhadhbi et al. 2012a, b). The early development of turbot from fertilization to hatching was thoroughly described by Tong et al. (2013), being a fundamental tool for teratogenic effect determination. Mhadhbi et al. (2010) reported that considering the short duration of the early life stage (ELS) turbot test and its high sensitivity, it is suitable for use as a standard test for marine fish. Mhadhbi et al. (2012a) also proved that the ELS turbot test is an excellent model for the study of ecotoxicity of contaminants in seawater.

To respond and to assess the impact of incidents involving HNS, the compilation of a comprehensive ecotoxicological dataset for marine organisms is a priority issue. Due to the high number and diversity of HNS transported by sea (Cunha et al. 2015), it is unrealistic to consider a full scientific ecotoxicological data survey for all such chemicals (Neuparth et al. 2011). In the context of the European funded project ARCOPOL, Neuparth et al. (2011) defined a priority list of 23 HNS, which were a subset from a previous list of the 100 most transported HNS in European Atlantic waters as described by HASREP (2005). Prioritization was based on available data from the literature considering the toxicity, carcinogenicity, bioaccumulation, biodegradation, physicochemical properties, incidence of previous spills and likelihood of future spillage at sea considering the transport volume of each HNS. The list produced by Neuparth et al. (2011) highlighted the gaps in ecotoxicological data for many priority HNS with some chemicals having little data or only data available for freshwater fauna, concluding that they would benefit from further investigation.

The aim of the current work was to build key toxicological knowledge on priority HNS to the marine environment (Neuparth et al. 2011) to support risk assessment studies, by testing in the laboratory their effects on two ecologically relevant and phylogenetically different marine animals. Produced data may also be used for regulatory and conservation purposes in contexts other than for HNS spills. 


\section{Materials and methods}

\section{Selection of HNS used}

Chemicals for ecotoxicological work were chosen taking into consideration (1) the inclusion in the HASREP (2005) list; (2) presence on the priority list established by Neuparth et al. (2011); (3) paucity of marine toxicological data (TOXnet); (4) behaviour in water according to the categories defined by the European Behaviour classification system (GESAMP 2002), which catalogues the behaviour of chemicals based on combinations of physical and chemical properties (Bonn Agreement 2015), by selecting compounds with different behaviours in water; and (5) consideration of the following parameters, when available: bioaccumulation, bioconcentration factor (BCF), biodegradation, acute and chronic toxicity, carcinogenesis (GESAMP and TOXnet), water solubility, partition coefficient, log Kow, organic matter adsorption constant and $\log$ Koc, in order to anticipate the most toxic compounds (Cunha et al. 2016). The chemicals (HNS) selected and some of the characteristics that most determine their behaviour in seawater are presented (Table 1).

Chemicals were tested for sublethal and lethal endpoints in one representative species each of a marine vertebrate and a marine invertebrate to better understand their acute toxicity during a spill at sea.

Stock solutions of aniline (CAS number: 62-53-3), butyl acrylate (CAS number: 141-32-2), m-cresol (CAS number: 108-39-4), cyclohexylbenzene (CAS number: 827-52-1), hexane (CAS number: 110-54-3) and trichloroethylene (CAS number: 79-01-6) at different concentrations were prepared in glass vials. Stock solutions were made by measuring appropriate volumes of the test chemical, considering the density and dissolving them in a solvent. The highest test chemical concentration was used to produce the appropriate stock dilution series, using pure dimethyl sulfoxide (DMSO) or acetone in the case of hexane, as solvents. The stock solutions were stored in the dark at $4{ }^{\circ} \mathrm{C}$. The experimental concentrations were obtained by diluting the $\mathrm{DMSO}$ /acetone-stock solutions in artificial seawater (ASW), making working solutions (dilution of 1:10,000). Therefore, subsamples of the primary stocks were used to make the definitive test dilution series. For all treatments, the final DMSO concentration was $0.01 \%(v / v)$ in the working solutions. This concentration was found to be non-toxic in other studies using turbot early life stages (ELS) (Mhadhbi et al. 2012a) and sea urchin (Bellas et al. 2005; Ribeiro et al. 2015). The experimental concentrations tested are shown in the supplementary materials (S1). Test concentrations were chosen on the basis of literature toxicological data (S2) and preliminary trials. Compounds were chosen based on their high probability of being spilt at sea and causing damage to the environment, according to HASREP (2005) and Neuparth et al. (2011). A dilution factor of 5 was

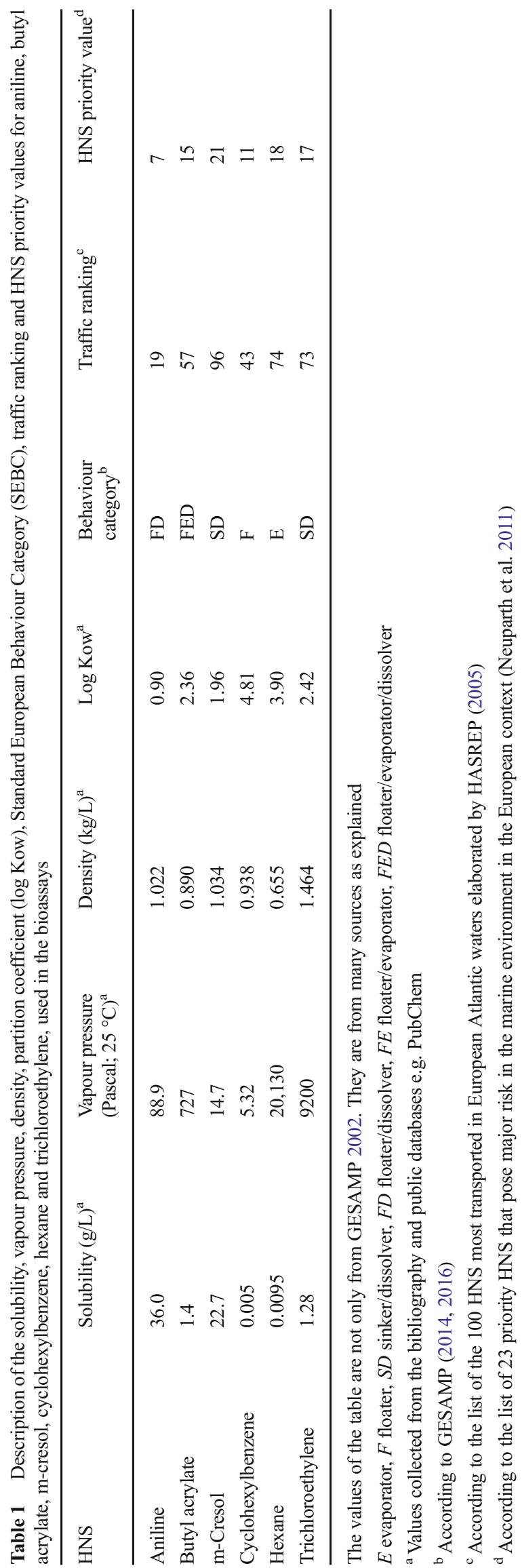


used in a preliminary range finding assay with sea urchin and then 1.5 with sea urchins and 2.5 dilution factors with turbot in the definitive assays. Following the range finder studies, more definitive tests were conducted to refine the estimates of endpoint concentration.

\section{Bioassay methodology}

Two toxicity bioassays were established using embryos of a deuterostome invertebrate, the sea urchin (P. lividus) and a vertebrate teleost fish (S. maximus).

\section{Sea urchin}

Adult sea urchins were collected from the intertidal rocky shores of northern Portugal during low spring tides. The animals were transported to the laboratory under controlled temperature and then were acclimated to laboratory conditions until the start of the assay. Within 30 min after fertilization, fertilized eggs of sea urchin were placed in 24-well plates with $3 \mathrm{~mL}$ of fresh test solution at a concentration of $50 \mathrm{eggs} / \mathrm{mL}$ to perform a sea urchin embryo test (SET). The 24-well plates were isolated with parafilm, and embryos were incubated at $20{ }^{\circ} \mathrm{C}$ in the dark for $48 \mathrm{~h}$ (Fernández and Beiras 2001; Ribeiro et al. 2015). Neither food nor aeration was provided during the bioassay. At the end of exposure time, embryos were fixed by adding two drops of $37 \%$ buffered formaldehyde until further observation. Embryogenesis success was recorded by applying two toxicity criteria: mean larval length and percentage $(n=15 \times 8)$ of fully developed four-arm pluteus larvae $(n=20 \times 8)$. The number of analysed individuals for the two criteria was based on Saco-Álvarez et al. (2010) and Ribeiro et al. (2015). The mean larvae length was defined as the distance between the apex and the end of the longest post-oral arm (Fig. 1). Larvae were considered

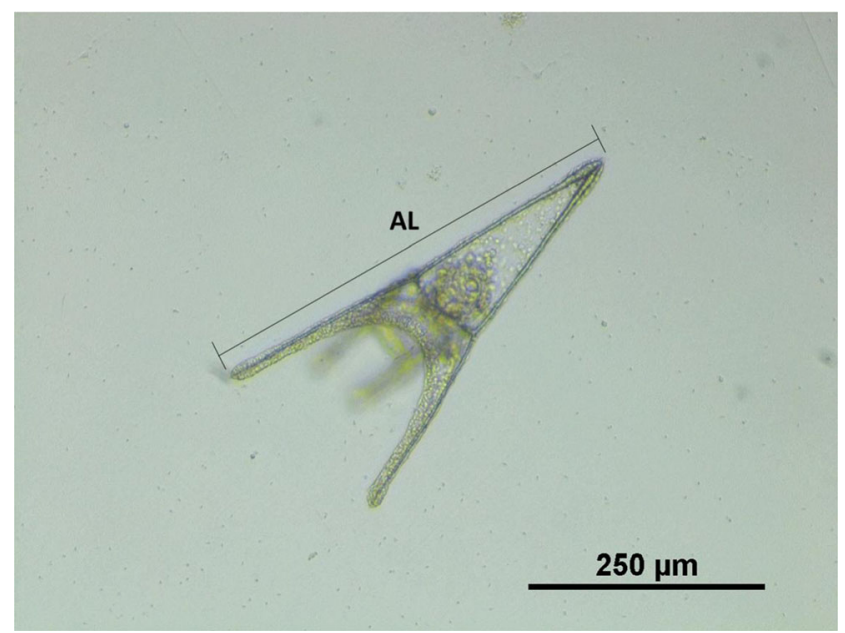

Fig. 1 Measure of maximum arm length dimension in sea urchin pluteus larvae. The four arms characteristic of this larval stage can be observed. $A L$ arm length normal by their pyramidal shape and the four fully separated arms (Saco-Álvarez et al. 2010). Larvae were measured and analysed directly in the 24-well plates using an inverted microscope (Nikon Eclipse TS100), equipped with a Nikon D5-Fi2 digital camera and software to perform measurements (Nikon Image Software). Changes to the normal development at $48 \mathrm{~h}$ post-fertilization (hpf) were recorded and presented as abnormal larvae.

For each toxicant, five and six concentrations plus a control (ASW) and a solvent control (pure DMSO or acetone in the sole case of hexane) were tested, in the preliminary and definitive assays, respectively (S1). Each treatment was replicated eight times, with each replicate test well containing $\sim 150$ larvae.

\section{Turbot}

Fertilized turbot eggs were provided by a commercial hatchery (Insuiña S.L., Mougás, Galicia, Spain), obtained from their own broodstock. Toxicity tests were also performed in 24-well plates, using 15-20 eggs in each well. Eggs were placed in the 24-well plates at the hatchery already immersed in the test solutions, immediately after fertilization, and transported to the laboratory inside styrofoam boxes at controlled temperature. Immediately after their arrival at the laboratory, plates were observed carefully, unfertilized eggs were discarded, and the density was adjusted to ten eggs/well. The bioassay was performed in an incubator, in the dark, at $14 \pm 0.5{ }^{\circ} \mathrm{C}$ and salinity of $30 \%$. Medium was changed every day, following a semi-static technique, and dead individuals were removed and counted. A modification relative to the turbot ELS performed by Mhadhbi et al. (2010) was the exposure of the eggs immediately after fertilization (1 hpf), instead of initiating exposure at $72 \mathrm{hpf}$. Accordingly, they were exposed for 4 days (1-100 hpf) as embryos and for 6 days as lecithotrophic larvae (nurtured by the yolk reserves, mouth still closed), a total of 10 days (220 hpf). Neither food nor aeration was provided during the bioassay.

For each toxicant, five concentrations of each HNS (S1), plus a control (ASW - no chemical added) and a solvent control (DMSO or acetone in the sole case of hexane), were tested. Each treatment was replicated six times, each replicate consisting of a well with ten eggs or larvae.

During the exposure to different concentrations of the six HNS, endpoints were observed throughout the 10-day exposure, at four selected developmental points (Table 2), when specific developmental events occur: $75 \%$ epiboly (53 hpf), $50 \%$ hatching (100 hpf), 100\% hatching (124 hpf) and mouth opening (220 hpf).

When the outer enveloping layer of the egg further flattens and differentiates into the epidermis, protecting the embryonic body at nearly $75 \%$, was the moment when $75 \%$ epiboly was considered to occur. At this point, the neural rod derived from 
Table 2 Developmental endpoints assessed in turbot embryos at the four sampling points established

\begin{tabular}{|c|c|c|c|c|}
\hline & \multicolumn{4}{|l|}{ Time (hpf) } \\
\hline & 53 & 100 & 124 & 220 \\
\hline Endpoints assessed & $\begin{array}{l}\text { Mortality } \\
75 \% \text { epiboly } \\
\text { Abnormal cellular masses }\end{array}$ & $\begin{array}{l}\text { Mortality } \\
\text { Hatching } \\
\text { Heart beat } \\
\text { Embryo malformations-organogenesis }\end{array}$ & $\begin{array}{l}\text { Mortality } \\
\text { Hatching } \\
\text { Embryo malformations } \\
\text { Yolk sac volume } \\
\text { Oil globule volume } \\
\text { Oil globule position }\end{array}$ & $\begin{array}{l}\text { Mortality } \\
\text { Yolk sac absorption } \\
\text { Oil globule volume } \\
\text { Oil globule position } \\
\text { Mouth opened } \\
\text { Embryo malformations } \\
\text { (others + jaw) } \\
\text { Larvae length }\end{array}$ \\
\hline
\end{tabular}

$h p f$ hours post-fertilization

ectoderm appears, the first somite also appears in the middle of the embryonic body, and the optic primordia are present. The different endpoints selected were observed using a stereomicroscope (LEICA). These developmental events have been well characterized and illustrated previously for $S$. maximus by Tong et al. (2013).

Hatching was defined as the rupture of the egg membrane, and partially as well as fully hatched larvae were counted as hatched (Mhadhbi et al. 2012a). At hatching, turbot lecithotrophic larvae possess a large yolk sac with a single oil globule, and the intestine is still closed at both ends. The frequency of heart beat gradually increases, there are clusters of pigment on the posterior to the fin-fold of newly hatched larva, and the larva remains motionless in the water (Tong et al. 2013).

Skeletal abnormalities seriously affect morphology of the fish, reduce growth and lower the market value of the product (Boglione et al. 2001). The skeletal deformities considered in the present work were abnormal dorsal curvature of trunk, abnormal dorsal curvature of tail, malformation of the jaw and malformation of the head.

Mortality was defined by coagulation of the embryos, missing heartbeat, failure to develop somites and a nondetached tail (Mhadhbi et al. 2012b).

\section{Statistics}

One-way analysis of variance followed by the Dunnett post hoc test was used to investigate the effects of HNS on $P$. lividus and $S$. maximus endpoints, by comparison to the control group, with determination of no observed effect concentration (NOAEC) and lowest observed apical effect concentration (LOAEC). Non-parametric tests, Kruskal-Wallis and Mann-Whitney $U$, were used when data did not meet the requirements of ANOVA. Semi-maximum response concentrations, $\mathrm{EC}_{50}$ and $\mathrm{LC}_{50}$, were determined using a Probit regression analysis. Pearson goodness-of-fit (chi-square) significance was considered at $p<0.05$ for all analyses (Zar 1999), and 95\% lower and upper confidence limits [95\% LCL; UCL] were presented. Statistical analyses were performed on IBM SPSS Statistics v.20.

\section{Results}

\section{Sea urchin bioassay}

With the exception of hexane, all HNS resulted in significant effects on development of sea urchin embryos (Table 3).
Table 3 Effect concentration values $\left(\mathrm{EC}_{10}\right)$ and limits for the six compounds tested in Paracentrotus lividus upon the measure of the length of the longest post-oral arm at $48 \mathrm{hpf}$

\begin{tabular}{|c|c|c|c|c|c|c|c|}
\hline & \multirow[t]{2}{*}{$\begin{array}{l}\mathrm{EC}_{10} \\
(\mathrm{mg} / \mathrm{L})\end{array}$} & \multirow[t]{2}{*}{$\begin{array}{l}{[\mathrm{LCL} ; \mathrm{UCL}]} \\
(\mathrm{mg} / \mathrm{L})\end{array}$} & \multicolumn{3}{|c|}{$\begin{array}{l}\text { Pearsons goodness-of- } \\
\text { fit test }\end{array}$} & \multirow[t]{2}{*}{$\begin{array}{l}\text { NOAEC } \\
(\mathrm{mg} / \mathrm{L})\end{array}$} & \multirow[t]{2}{*}{$\begin{array}{l}\text { LOAEC } \\
(\mathrm{mg} / \mathrm{L})\end{array}$} \\
\hline & & & $\chi^{2}$ & $d f$ & $\begin{array}{l}\text { Slope } \\
\text { sig. }\end{array}$ & & \\
\hline Aniline & 0.807 & {$[0.409 ; 1.907]$} & 17.132 & 10 & 0.000 & 0.026 & 0.039 \\
\hline Butyl acrylate & 0.358 & {$[0.217 ; 0.527]$} & 14.190 & 8 & 0.000 & 0.158 & 0.237 \\
\hline m-Cresol & 0.345 & {$[0.147 ; 3.523]$} & 16.359 & 9 & 0.000 & 0.021 & 0.032 \\
\hline Cyclohexylbenzene & 3.102 & {$[2.289 ; 4.268]$} & 22.122 & 10 & 0.000 & 0.658 & 0.988 \\
\hline Hexane & ND & ND & 22.329 & 10 & 0.259 & $>70$ & $>70$ \\
\hline Trichloroethylene & ND & ND & 81.456 & 10 & 0.000 & 1.19 & 1.78 \\
\hline
\end{tabular}

Probit statistics were obtained through a Pearson goodness-of-fit test

LCL 95\% lower concentration limit, UCL 95\% upper concentration, limit, ND not determined 
m-Cresol had the lowest NOAEC and LOAEC 0.032 and $0.160 \mathrm{mg} / \mathrm{L}$, respectively (preliminary test), 0.021 and $0.032 \mathrm{mg} / \mathrm{L}$, respectively (definitive test), and also the lowest $\mathrm{EC}_{10}-0.345 \mathrm{mg} / \mathrm{L}$, while hexane was the least toxic compound in both preliminary and definitive tests performed with P. lividus (Table 3). It was not possible to calculate an LOAEC or $\mathrm{EC}_{10}$ for hexane because there was not a significant effect of any of the test concentrations on the length of the arm (Table 3). Therefore, at the concentrations tested, hexane did not affect the length of the longest arm of $P$. lividus larvae, and taking into account the LOAEC obtained on SET, the toxicity rank of the six chemicals tested was $\mathrm{m}$-cresol $>$ aniline $>$ butyl acrylate $>$ cyclohexylbenzene $>$ trichloroethylene, while using $\mathrm{EC}_{10}$, the toxicity rank was $\mathrm{m}$-cresol $>$ butyl acrylate $>$ aniline $>$ cyclohexylbenzene. It was not possible to determine $\mathrm{EC}_{10}$ for trichloroethene because it falls beyond the maximal concentration tested $(6 \mathrm{mg} / \mathrm{L})$.

\section{Turbot bioassay}

Hexane was the only HNS that had a significant effect on turbot larvae. The endpoints affected were hatching rate at $124 \mathrm{hpf}$ and cumulative mortality rate at the end of the experiment (220 hpf). NOAEC and LOAEC values were 2.8 and $7.0 \mathrm{mg} / \mathrm{L}$, respectively (Table 4 and Fig. 2). $\mathrm{EC}_{50}$ on hatching rate at $124 \mathrm{hpf}$ was $11.64 \mathrm{mg} / \mathrm{L}$ [95\% 4.12; 202.06], while the $\mathrm{LC}_{50}$ at 220 -hpf value was $1.53 \mathrm{mg} / \mathrm{L}$ [95\% $\left.0.67 ; 5.89\right]$ (Table 4).

None of the other five chemicals tested had significant effects on turbot eggs-larvae at the concentrations tested. Therefore, for these chemicals, the effective NOAECs and LOAECs were estimated to be greater than the highest nominal concentrations tested.

\section{Discussion}

The compounds tested here were carefully chosen as representative of a chemical that is frequently transported in bulk, pose risk to the environment, has little aquatic and in particular marine toxicity data available (S2), represents one of the Bonn Agreement behaviour categories and is anticipated to be toxic based on its physicochemical properties. Aniline and m-cresol were the most toxic compounds with LOAEC values in the SET ranging between 0.01 and $0.1 \mathrm{mg} / \mathrm{L}$, while trichloroethylene was the least toxic with SET's NOAEC values in the range between 1 and $10 \mathrm{mg} / \mathrm{L}$. A similar rank was observed when analysing $\mathrm{EC}_{10}$ data. Surprisingly, hexane was the only HNS of the six analysed that did not have an effect on the length of the longest arm of sea urchin larvae, at the range of concentrations tested and, at the same time, the only one that affected the egg hatching rate and cumulative mortality rate of turbot larvae, although only at the highest concentration tested (7 mg/L, Fig. 2).

Toxicity tests using ELS play an important part in risk assessment as they are generally considered more sensitive to toxic agents. The sensitivity of ELS tests is probably due to a larger body surface-to-volume ratio of eggs, embryos and larvae; their generally undifferentiated epithelia; and the vulnerability of the developmental processes (Oberemm 2000). The different permeability and composition of the eggshell of both organisms may be responsible for the disparity in the response to the compounds when comparing embryos of both species. Turbot eggs have a much thicker chorion, which protects the developing embryo for nearly 4 days before hatching. In contrast, in sea urchin eggs, the envelope lasts only up to $24 \mathrm{~h}$. The lipid content of the egg/chorion of both species does not explain the different effects of the chemicals, considering that hexane is a very good lipid solvent since they have a similar total lipid content. Lipids are about $12.1 \%$ of P. lividus egg dry weight (Pais et al. 2011), while in turbot eggs, lipids are 13-14\% dry weight (Silversand et al. 1996), and so, similar partition coefficients may be expected regarding this parameter, for the same chemical in both species.

The results of SET largely reflect the physicochemical properties of the test chemical and its behaviour in water (Bonn Agreement 2015) of the six chemicals tested (Table 1). The movement of a chemical between the air and water is affected by its volatilization and its water solubility. The high vapour pressure of hexane and trichloroethylene means that it is very likely that the concentration of these chemicals in solution will rapidly decrease during a test or when present in the sea following a spill. Hexane also shows one of the lowest potential solubilities (Table 1). Although all

Table 4 Hexane concentration values and limits of $\mathrm{EC}_{50}$ and $\mathrm{LC}_{50}$ in Scophthalmus maximus, for the parameters hatching rate at 124 hpf and cumulative mortality rate at $220 \mathrm{hpf}$, respectively

\begin{tabular}{lllllll}
\hline & $\begin{array}{l}\text { Semi-maximum response } \\
\text { concentration }(\mathrm{mg} / \mathrm{L})\end{array}$ & LCL & UCL & Chi-square & $d f$ & Slope sig. \\
\hline Hatching rate (124 hpf) & 11.639 & 4.123 & 202.062 & 798.0 & 34 \\
Cumul. mortality rate (220 hpf) & 1.513 & 0.673 & 5.889 & 1164.2 & 34 & 0.000 \\
\hline
\end{tabular}

Probit statistics were obtained following Pearson goodness-of-fit test, on the obtained values at six hexane concentrations. $L C L 95 \%$ lower concentration limit, UCL 95\% upper concentration limit 


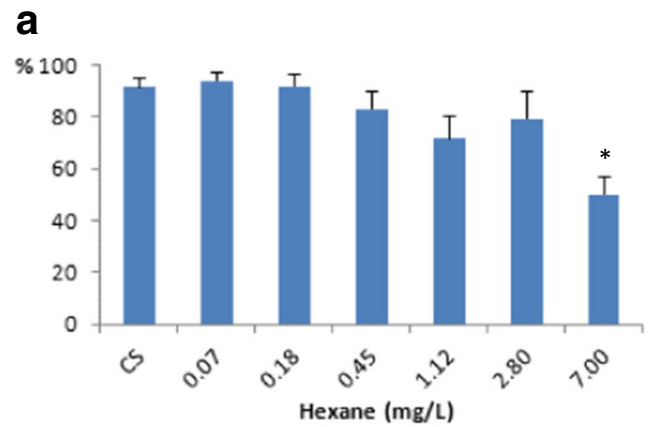

Fig. 2 a Hatching rate (\%) at $124 \mathrm{hpf}$ and b cumulative mortality rate (\%) at $220 \mathrm{hpf}$ of turbot larvae for six hexane concentrations. Differences were analysed as compared to solvent control (Cs) through the post hoc

the six tested chemicals have a maximum solubility, under the conditions described, well within the test concentration range, the high vapour pressure of hexane and trichloroethylene possibly led to reduced exposure concentrations and hence lower toxicity (except in the case of hatching rate of turbot larvae at $124 \mathrm{hpf}$ and cumulative mortality rate at $220 \mathrm{hpf}$ ). m-Cresol and aniline were the most toxic of the chemicals tested, which is probably related to the physicochemical properties like high solubility in water. Also, m-cresol is a sinker-dissolver (SD), and although sea urchin larvae swim in the water column, they rest at the bottom, where possibly the concentration of cresol was the highest.

In the turbot ELS bioassay with hexane, the most sensitive endpoint was cumulative mortality at $220 \mathrm{hpf}(1.5 \mathrm{mg} / \mathrm{L})$, as compared to egg hatching rate $(11.6 \mathrm{mg} / \mathrm{L})$. A similar result was observed for previous turbot ELS bioassays using polycyclic aromatic hydrocarbons (PAHs), metals (Mhadhbi et al. 2010), pesticides (Mhadhbi et al. 2012b) and polybrominated diphenyl ethers (PBDEs) (Mhadhbi et al. 2012a) where it was found that embryos are more tolerant than hatched larvae. Embryo's tolerance was nearly two times higher in the case of PAH, metals and some PBDEs. In the present work, regarding hexane, tolerance was seven times higher in embryos as compared to hatched larvae. The higher tolerance of embryos has been attributed to the protection that the chorion confers to embryos, acting as a barrier for some toxicants (Hallare et al. 2006; Barry et al. 1995; Humphrey and Klumpp 2003).

Since after hatching turbot larvae were still exposed to HNS for further 5-6 days and despite the renewal of media every day, they did not respond to any of the tested compounds, except to hexane. Hence, it seems that SET is more sensitive to the priority HNS tested than turbot larvae. However, Mhadhbi et al. (2010) have reported that considering the short duration of the turbot ELS and its high sensitivity as compared to other fish species, it is suitable for use as a standard test for marine fish. Despite differences in sensitivity, both tests are complimentary, and when e.g. neurotoxic compounds are being tested, vertebrates or crustaceans are usually more appropriate because of the higher complexity of their

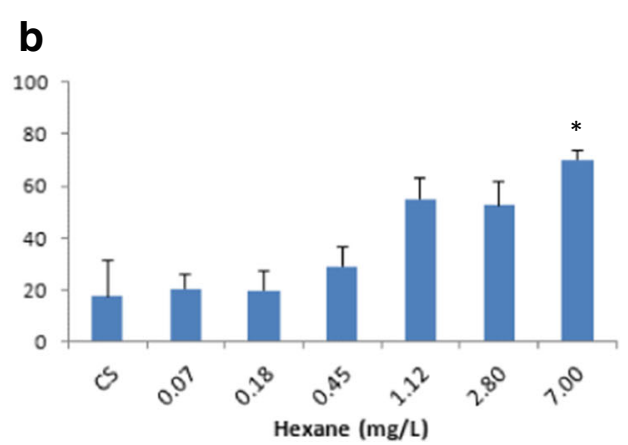

Dunnett test. Results represent average values \pm standard error. Asterisk indicates significant differences to control $(p<0.05)$

nervous system, which confers upon them a higher sensitivity to these types of compounds. This is the case for hexane, for which the nervous system is the primary target of toxicity (US EPA 2005). Accordingly, comparing turbot $\mathrm{LC}_{50}$ for hexane to those available for other aquatic species (S2), rotifer (Brachionus plicatilis) neonates (Snell et al. 1991; Ferrando and Andreu-Moliner 1992) and Artemia salina nauplii (Abernethy et al. 1986), the test with turbot embryos was confirmed to be more sensitive (Table 4). It was $100 \times$ more sensitive than for rotifers and $2 \times$ more sensitive than $A$. salina. Contrarily, hatching rate $\mathrm{EC}_{50}$ was much less sensitive than all the other $\mathrm{EC}_{50}$ values described in the bibliography, namely on Skeletonema costatum photosynthesis (Brooks et al. 1977) and A. salina immobilization (Foster and Tullis 1995).

Regarding the other endpoints analysed in the sea urchin SET (malformations) and turbot ELS (Table 3), none of the various HNS analysed had a significant effect on any endpoint. No significant abnormalities were observed after exposure, in any of the organisms, as compared to the control, showing that these HNS are not teratogenic at the concentrations tested.

Comparing the SET NOAEC results to the other species data from the literature indicates that SET is in a similar order of magnitude of sensitivity to aniline, trichloroethylene and hexane toxicity but potentially more sensitive to m-cresol. Regarding NOAEC values in chronic assays for aniline with the freshwater crustacean, Daphnia magna, 21-day reproduction test of $0.004 \mathrm{mg} / \mathrm{L}$ (Kühn et al. 1989) and fathead minnow fish, Pimephales promelas, ELS growth test of $0.422 \mathrm{mg} / \mathrm{L}$ (Russom 1993), the values obtained in the present study in SET for aniline are between that range of values (Table 3). However, the LOAEC values observed in SET ( 0.2 and $0.039 \mathrm{mg} / \mathrm{L}$, for preliminary and definitive tests, respectively) indicate that it is more sensitive to aniline than $P$. promelas ELS assay (Russom 1993), corroborating also the low sensitivity observed in the 10-day turbot ELS (LOAEC $>0.320 \mathrm{mg}$ / L). Recently, de los Santos et al. (2015), using a 25-day partial-life cycle test with Gammarus locusta, reported that a 
concentration as low as $0.0005 \mathrm{mg} / \mathrm{L}$ led to a reduction of newborn production, a concentration below that recorded here to affect sea urchin embryo development. These results provide preliminary information that is of value when assessing the risk of aniline spills to different marine species and habitats, as well as the choice of target organisms to test.

For butyl acrylate (Bringmann and Kuhn 1977; Paulet and Vidal 1975) and cyclohexylbenzene (Passino-Reader et al. 1997), only data reporting acute response, mostly $L_{50}$ values of freshwater fauna are available, which makes the results reported here valuable in filling gaps of knowledge of the effects of such chemicals in the marine environment (Table 3) but makes comparisons to other seawater species data difficult (S2). A good literature review of benchmarks and description of test conditions for these six HNS is presented by Neuparth et al. (2011).

Regarding m-cresol, only $\mathrm{EC}_{50}$ values were available for other species comparisons again and the $\mathrm{EC}_{10}$ values obtained with SET for the length of the arm revealed were around 100× lower than the $\mathrm{EC}_{50}$ values obtained for another sea urchin (Strongylocentrotus droebachiensis) and cod (Gadus morhua) embryos (Falk-Petersen et al. 1985), where multiple effects are reported as one result (death, pathology, inhibition of cleavage and differentiation and pigment defects).

Finally, regarding data reporting acute toxicity of hexane and trichloroethylene to seawater fauna, a few $\mathrm{LC}_{50}$ values only are available from the literature. For trichloroethylene, $\mathrm{LC}_{50}$ values of 48-96-h acute assays ranged from $2 \mathrm{mg} / \mathrm{L}$ in the crustacean Mysidopsis bahia (Borthwick 1977) to $99 \mathrm{mg} /$ $\mathrm{L}$ in the fish Cyprinodon variegatus (Pearsons and McConnell 1975), while in the present study, NOAEC and LOAEC values observed for trichloroethylene in the SET were 1.19 and $1.78 \mathrm{mg} / \mathrm{L}$, respectively. These data suggest that SET is probably of a similar order of magnitude of sensitivity to those other species.

Since there is a paucity of knowledge on HNS effects on marine biota and relatively few data are available on the HNS ecotoxicology, those data originating mostly from assays performed with freshwater organisms, additional species toxicity data obtained here will be of value in developing post-spill risk assessments for these chemicals and are essential to better anticipate the impact of HNS in marine species, therefore improving preparedness and response at the operational level.

Acknowledgements The present work was developed within the framework of the ARCOPOLplus project-Improving maritime safety and Atlantic Regions' coastal pollution response through technology transfer, training \& innovation (contract nr. 2011-1/150) - funded by the Atlantic Area Transnational Programme (Priority 2: Marine Environment and Renewable Energy) with support of the European Regional Development Fund (ERDF) and ARCOPOL Platform. We also acknowledge the Portuguese Foundation for Science and Technology (FCT) through the strategic project "UID/Multi/04423/2013".

\section{References}

Abernethy S, Bobra AM, Shiu WY, Wells PG, Mackay D (1986) Acute lethal toxicity of hydrocarbons and chlorinated hydrocarbons to two planktonic crustaceans: the key role of organism-water partitioning. Aquat Toxicol 8:163-174

Barry MJ, Logan DC, van Dam RA, Holdway DA (1995) Effect of age and weight-specific respiration rate on toxicity of esfenvalerate pulse - exposure to the Australian crimson-spotted rainbowfish (Melanotaenia fluviatilis). Aquat Toxicol 32:115-126

Bellas J, Beiras R, Mariño JC, Fernández N (2005) Toxicity of organic compounds to marine invertebrates' embryos and larvae: a comparison between sea urchin embryogenesis bioassay and alternative test species. Ecotoxicology 14:337-353

Boglione C, Gagliardi G, Scardi M, Cataudella S (2001) Skeletal descriptors and quality assessment in larvae and post-larvae of wild-caught and hatchery-reared gilthead sea bream (Sparus aurata L. 1758). Aquaculture 192:1-22

Bonn Agreement (2015) Bonn agreement counter pollution manual. Available at: http://www.bonnagreement.org/site/assets/files/3946/ bonn_agreement_counter_pollution_manual-1.pdf. Accessed Dec 2015

Borthwick PW (1977) Summarized results of toxicity tests with sheepshead minnows (Cyprinodon varlesatus) and grass shrimp (Palaemonetes pugio). US Environmental Protection Agency. Environmental Research Laboratory, Gulf Breeze, Florida

Bringmann G, Kuhn R (1977) Results of the damaging effect of water pollutants on Daphnia magna. Zeitschrift fur Wasser - und Abwasserforschung 10:161-166

Brooks JM, Fryxell GA, Reid DF, Sackett WM (1977) Gulf underwater flare experiment (GUFEX): effects of hydrocarbons on phytoplankton. In: Giam CS (ed) Proceedings of pollution effects on marine organisms. D.C. Heath Co., Lexington, MA, pp 45-75

CEFAS (2009) UK risk assessment for hazardous and noxious substances - RP 593

Cunha I, Moreira S, Santos MM (2015) Review on hazardous and noxious substances (HNS) involved in marine spill incidents - an online database. J Hazard Mater 285:509-516

Cunha I, Oliveira H, Neuparth T, Torres T, Santos MM (2016) Fate, behaviour and weathering of priority HNS in the marine environment: an online tool. Mar Pollut Bull 111:330-338

de los Santos CB, Neuparth T, Torres T, Martins I, Cunha I, Sheahan D, McGowan T, Santos MM (2015) Ecological modelling and toxicity data coupled to assess population recovery of marine amphipod Gammarus locusta: application to disturbance by chronic exposure to aniline. Aquat Toxicol 163:60-70

Falk-Petersen IB, Kjorsvik E, Lonning S, Naley AM, Sydnes LK (1985) Toxic effects of Hydroxylated aromatic hydrocarbons on marine embryos. Sarsia 70:11-16

Fernández N, Beiras R (2001) Combined toxicity of dissolved mercury with copper, lead and cadmium on embryogenesis and early larval growth of the Paracentrotus lividus Sea-urchin. Ecotoxicology 10: 263-271

Ferrando MD, Andreu-Moliner E (1992) Acute toxicity of toluene, hexane, xylene, and benzene to the rotifers Brachionus calyciflorus and Brachionus plicatilis. Bull Environ Contam Toxicol 49:266-271

Foekema EM, Deerenberg CM, Murk AJ (2008) Prolonged ELS test with the marine flatfish sole (Solea solea) shows delayed toxic effects of previous exposure to PCB 126. Aquat Toxicol 90:197-203

Foster GD, Tullis RE (1995) Quantitative structure-toxicity relationships with osmotically stressed Artemia salina Nauplii. Environmental Pollution A 38:273-281

GESAMP (2002) The revised GESAMP hazard evaluation procedure for chemical substances carried by ships. GESAMP reports and studies no. 64 
GESAMP (2014) (IMO/FAO/UNESCO-IOC/WMO/WHO/IAEA/UN/ UNEP Joint group of experts on the scientific aspects of marine environmental protection). Revised GESAMP hazard evaluation procedure for chemical substances carried by ships, 2nd edition. Rep. Stud. GESAMP No. 64, 126 pp

GESAMP (2016) Composite list. ANNEX 5 - Updated GESAMP composite list. Available at: https://edocs.imo.org/Final Documents/ English/PPR 1-CIRC.3 (E).docx

Hallare A, Nagel K, Köhler HR, Triebskorn R (2006) Comparative embryotoxicity and proteotoxicity of three carrier solvents to zebrafish (Danio rerio) embryos. Ecotoxicol Environ Saf 63:378388

HASREP (2005) Response to harmful substances spilt at sea. Prepared by The Alliance of Maritime Regional Influences in Europe (AMRIE). Centre de Documentation, de Recherche et d'Expérimentations sur les Pollutions Accidentelles des eaux, (CEDRE) and TNO Built Environment and Geosciences, The Netherlands

His E, Beiras R, Seaman MNL. 1999. The assessment of marine pollution-bioassays, with bivalve embryos and larvae. In: Southward AI, Tyler PA, Young CM (eds) Advances in marine biology 37

Humphrey C, Klumpp DW (2003) Toxicity of chloropyrifos to early life history stages of eastern rainbowfish Melanotaenia splendida splendida (Peters 1866) in tropical Australia. Environ Toxicol 18: 418-427

IMO - International Maritime Organisation (2000) Protocol on preparedness, response and co-operation to pollution incidents by hazardous and noxious substances (OPRC-HNS protocol)

Kühn R, Pattard M, Pernak KD, Winter A (1989) Results of the harmful effects of water pollutants to Daphnia magna, in the 21 day reproduction test. Water Res 23:501-510

Mamaca E, Bechmann RK, Torgrimsen S, Endre Aas E, Bjørnstad A, Baussant T, Le Floch S (2005) The neutral red lysosomal retention assay and Comet assay on haemolymph cells from mussels (Mytilus edulis) and fish (Symphodus melops) exposed to styrene. Aquat Toxicol 75:191-201

Mhadhbi L, Boumaiza M, Beiras R (2010) A standard ecotoxicological bioassay using early life stages of the marine fish Psetta maxima. Aquat Living Resour 23:209-216

Mhadhbi L, Fumega J, Boumaiza M, Beiras R (2012a) Acute toxicity of polybrominated diphenyl ethers (PBDEs) for turbot (Psetta maxima) early life stages (ELS). Environ Sci Pollut Res 19:708-717

Mhadhbi L, Toumi H, Boumaiza M, Aloui N (2012b) Toxicity of three selected pesticides (Alachlor, Atrazine and Diuron) to the marine fish (turbot Psetta maxima). Afr J Biotechnol 11:11321-11328

Nacci DE, Jackim E, Walsh R (1986) Comparative evaluation of three marine toxicity tests: sea urchin embryo growth test, sea urchin sperm cell toxicity test and microtox. Environ Toxicol Chem 5: $521-529$

Neuparth T, Moreira S, Santos MM, Reis-Henriques MA (2011) Hazardous and noxious substances (HNS) in the marine environment: prioritizing HNS that pose major risk in a European context. Mar Pollut Bull 62:21-28

Oberemm A (2000) The use of refined zebra fish bioassay for the assessment of aquatic toxicity. Lab Anim 29:32-40
Pais A, Saba S, Rubattu R, Meloni G, Montisci S (2011) Proximate composition of edible sea urchin Paracentrotus lividus roe commercialized in Sardinia. Biol Mar Mediterr 18:390-391

Passino-Reader DR, Hickey JP, Ogilvie LM (1997) Toxicity to Daphnia pulex and QSAR predictions for polycyclic hydrocarbons representative for great lakes contaminants. Bulletin Environmental Contamination and Toxicology 59:834-840

Paulet G, Vidal M (1975) Toxicity of some acrylic and methacrylic esters of acrylamide and polyacrylamides. Archives des Maladies Professionnelles de Medecine du Travail et de Securite Sociale 36: $58-60$

Pearsons CR, McConnell G (1975) Chlorinated C1 and C2 hydrocarbons in the marine environment. Proc R Soc Lond Ser B 189:305-332

Purnell K. 2009. Are HNS spills more dangerous than oil spills? Conference Proceedings, Interspill, Marseille, 12-14 May 2009

Ribeiro S, Torres T, Martins R, Santos MM (2015) Toxicity screening of diclofenac, propranolol, sertraline and simvastatin using Danio rerio and Paracentrotus lividus embryo bioassays. Ecotox Environ Saf 114:67-74

Ringwood AH (1991) Short-term accumulation of cadmium by embryos larvae, larvae, and adults of Hawaiian bivalve Isognomon californicum. J Exp Mar Biol Ecol 149:55-66

Russom CL (1993) Acute and early life stage toxicity data. June 21 Memo from US EPA, Duluth, MN to R. Spehar US EPA, Duluth, MN, p. 41

Saco-Álvarez L, Durán I, Lorenzo JI, Beiras R (2010) Methodological basis for the optimization of a marine sea-urchin embryo test (SET) for the ecological assessment of coastal water quality. Ecotoxicol Environ Saf 73:491-499

Salamanca MJ, Fernandez N, Cesar A, Anton R, Lopez P, Delvalls A (2009) Improved sea-urchin embryo bioassay for in situ evaluation of dredged material. Ecotoxicology 18:1051-1057

Silversand C, Norberg B, Haux C (1996) Fatty-acid composition of ovulated eggs from wild and cultured turbot (Scophthalmus maximus) in relation to yolk and oil globule lipids. Mar Biol 125: 269-278

Snell TW, Moffat BD, Janssen C, Persoone G (1991) Acute toxicity tests using rotifers. III. Effects of temperature, strain, and exposure time on the sensitivity of Brachionus plicatilis. Environ Toxicol Water Qual 6:63-75

Solé M, Lima D, Reis-Henriques MA, Santos MM (2008) Stress biomarkers in juvenile Senegal sole, Solea senegalensis, exposed to the water-accommodated fraction of the "Prestige" fuel oil. Bull Environ Contam Toxicol 80:19-23

Tong XH, Xu SH, Liu QH, Li J, Xiao ZZ, Ma DY (2013) Stages of embryonic development and changes in enzyme activities in embryogenesis of turbot (Scophthalmus maximus L.) Aquac Int 21: $129-142$

US EPA (2005) Toxicological review of n-hexane in support of summary information on the integrated risk information system (IRIS). National Center for Environmental Assessment, Washington, DC EPA/635/R-03/012

Zar JH (1999) Biostatistical analysis, fourth edn. Prentice Hall, New Jersey $663 \mathrm{p}$ 